\title{
Connectedness via $b$ - open sets
}

\author{
SHYAMAPADA MODAK and TAKASHI NOIRI
}

\section{ABSTRACT.}

In this paper we define a new type of connectedness by using $b$ - open sets and discuss the relationship between this connectedness and various types of connectedness already defined in topological spaces.

\section{REFERENCES}

[1] Andrijević, D., On b - open sets, Mat. Vesnik, 48 (1996), 59-64

[2] Caldas, M., Jafari, S. and Latif, R. M., $b$ - open sets and a new class of functions, Pro Mathematica Peru, 23 (2009), No. 45-46, 155-174

[3] Ekici, E., On $\gamma$ - US spaces, Ind. J. Math., 47 (2005), No. 2-3, 131-138

[4] Ekici, E., On $\gamma$-normal spaces, Bull. Math. Soc. Sci. Math. Roumanie (N.S.), 50(98) (2007), No. 3, 259-272

[5] Ekici, E., On separated sets and connected spaces, Demonstratio Math., 40 (2007), No. 1, 209-217

[6] El-Atik, A. A., A study of some study of some types of mappings on topological spaces, M. Sc. Thesis, Tanta University, 1997

[7] El-Atik, A. A., Abu Donia H. M. and Salama, A. S., On b-connectedness and b-disconnectedness and their applications, J. Egypt. Math. Soc., 21 (2013), 63-67

[8] Modak, S. and Noiri, T., A weaker form of connectedness, Communicated

[9] Mrsevic, M. and Andrijevic, D., On $\theta$ - connectedness and $\theta$ - closure spaces, Topology Appl., 123 (2002), No. 1, 157-166

[10] Noiri, T. and Modak, S., Half b - connectedness in topological spaces, communicated

[11] Velicko, N. V., On the theory of H - closed topological spaces, Sibirskii Math. Z., 8 (1967), 754-763; Siberian Math J., 8 (1967), 569-579

UNIVERSITY OF GOUR BANGA

DEPARTMENT OF MATHEMATICS

P.O. MOKDUMPUR, 732 103, MALDA, INDIA

E-mail address: spmodak2000@yahoo.co.in

2949-1 SHIOKITA-CHO

HINAGU, YATSUSHIRO-SHI

KUMOMOTO-KEN, 869-5142, JAPAN

E-mail address: t.noiri@nifty.com 